\title{
MIMO Based Microstrip Patch Antenna with Tree Shape Patch for 5G Applications
}

\author{
Jitendra Dubey, Santosh Sharma, Vandana Vikas Thakare
}

\begin{abstract}
G$ technology is the latest technology in market for high data rate communication based applications. There are some problems like signal blocking and attenuation occur at very high data rate and become a problem for $5 G$ communication. This problem can be solved by using MIMO based antennas. Microstrip patch antenna is used for high frequency antenna applications. Multiple array MIMO based microstrip patch antenna is very suitable for high data rate $5 G$ applications. CST software is used for designing and simulation of the proposed MIMO antenna. The proposed work is $2 \times 2$ array of MIMO microstrip patch antenna with a tree shape patch and full ground, which is providing better bandwidth of $69 \mathrm{MHz}$ at 3.5 $\mathrm{GHz} 5 \mathrm{G}$ frequency. It is also providing return loss of $-24.1 \mathrm{~dB}$ which is better than previous work which has achieved return loss of $\mathbf{- 1 9 d B}$ only. Proposed antenna is very suitable for $5 G$ applications including mobile communication, WLAN etc.
\end{abstract}

Keywords: Multiband Antenna, MIMO (Multiple Input Multiple Output), 5G, Wideband, MPA (Microstrip Patch Antenna), FR-4, return loss, antenna gain, radiation pattern.

\section{INTRODUCTION}

In this new era of advancement, speed of data communication becomes very important. New 5G technology is planning to launch to fulfill this high data rate requirement. 5G technology is capable of serving speed in Gbps. For data communication at high frequencies Microstrip Patch Antenna (MPA) is used due to its light weight, low costing, and it is also very easy to fabricate. In 5G architecture, network consists of large number of small cells and these cells are capable of providing high data rate with lesser requirement of power. The only disadvantage of $5 G$ is due to this high data rate, signal blocking and attenuation increases [1]. It is found that MIMO based MPA can be used to resolve these problems.

The main factor of these 5G antennas is the implementation of MIMO to increase the speed by $10-100$ times as compared to $4 \mathrm{G}$. Interference alignment and multicell processing can be used with MIMO to reduce interference [6].

Manuscript received on July 15, 2021.

Revised Manuscript received on July 22, 2021.

Manuscript published on July 30, 2021.

* Correspondence Author

Jitendra Dubey*, Department of Electronics, Madhav Institute of Technology \& Science Gwalior (M.P.), India. Email: jitendradubey220601@gmail.com

Santosh Sharma, Department of Electronics, Madhav Institute of Technology \& Science Gwalior (M.P.), India. Email: santos_gwl@mitsgwalior.in

Vandana Vikas Thakare, Department of Electronics, Madhav Institute of Technology \& Science Gwalior (M.P.), India. Email: vandana@mitsgwalior.in

(C) The Authors. Published by Blue Eyes Intelligence Engineering and Sciences Publication (BEIESP). This is an open access article under the CC BY-NC-ND license (http://creativecommons.org/licenses/by-nc-nd/4.0/)
Using these techniques (multi-cell processing and interference alignment) the cell size is reduced by fixing femto cells or small cells but this will increase the cost of additional equipment in addition to increasing interference, therefore, the most appropriate option is to use MIMO technology. Frequency reuse technique can be used to utilize losses due to propagation and this can be done by making small cell base stations which are also called as pico-cells \& femto-cells [2]. The environmental conditions like rains also creates problem in propagation of higher frequencies. Snowfall, fog, rain etc leads to bad transmission. This also leads to bad strength and bad signal quality due to attenuation by atmosphere. This issue can be solved by introducing directional antenna with high gain. CST MICROWAVE STUDIO is a fully featured software package for electromagnetic analysis and design in the high frequency range [7]. The software contains four different simulation techniques (transient solver, frequency domain solver, Eigen mode solver, modal analysis solver) which best fit their particular applications.

2x2 MIMO based MPA is designed in this paper for the applications of 5G technology. Four array of tree shape design is placed with a ground plane. The results are proving a bandwidth of $69 \mathrm{MHz}(3.503 \mathrm{GHz}-3.572 \mathrm{GHz})$ at a return loss of $-24.1 \mathrm{~dB}$ with a resonant frequency of $3.53 \mathrm{GHz}$.

\section{MIMO SYSTEM}

Any trans-receiver system has one oscillator, one band pass filter (BPF), one low noise amplifier (LNA) and an antenna. Slotted microstrip antenna is designed out of microstrip patch antenna. In MIMO technology, several antenna elements in the single unit is used at both source and destination units. These multiple antennas are used together to reduce errors as well as increase data rates [8]. MIMO is a smart antenna model which is used for 5G, other such smart models are MISO (Multiple input, Single output) and SIMO (Single input, Multiple output). While conventional systems make use of single antenna at both source and destination. Multipath effects create a problem in MIMO system. Scattering of EM signal occur due to high density obstacles like valley, trees, buildings, cables etc, this leads to problems like delay in signal, signal fading, cut off of signal etc [5][10]. Such issues lead to problems in communication system like decrease in data rate and errors in signal.

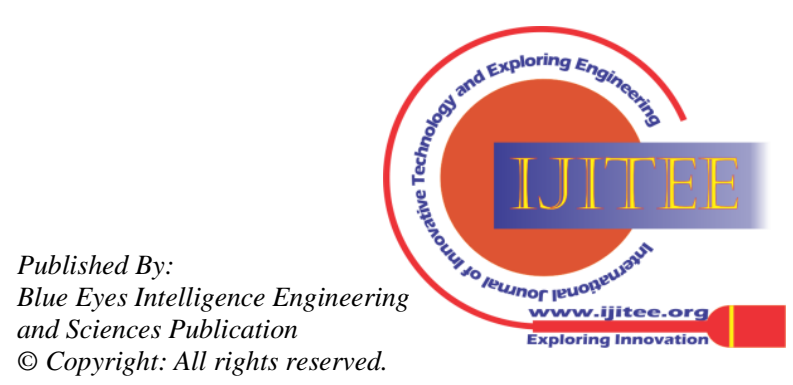




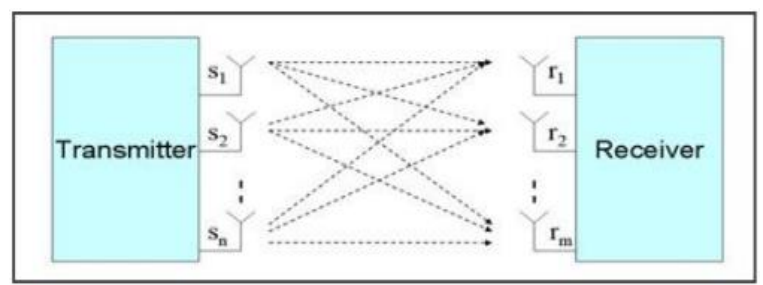

Fig.1: MIMO System

The use of multiple antennas in MIMO system reduces the effect of delay of signal because of multipath or missing signal since multiple signals can be sent at once. Television, Wireless local area network, mobile communication systems uses MIMO systems for better transmission [4].

$C=B \log _{2}\left(1+\frac{S}{N}\right)$

As per the above equation, it can be seen that the main parameter to achieve maximum speed of communication is bandwidth because it is directly proportional to capacity while SNR defines the signal transmission quality. One of the advantages of MIMO systems is that it can increase channel capacity without changing the bandwidth [3]. Another advantage of MIMO is its linear increase in channel capacity with respect to increase in antenna counts while for all others like SISO, SIMO \& MISO channel capacity increases logarithmically. There is only one path in between each of the source \& destination pairs, it indicates the transmission of same information in multiple directions and thus multiple copy of same information will be received at destination end which indicates reliability [9][11].

\section{ANTENNA DESIGN}

2x2 MIMO RMPA with tree shape design is printed on the one side of the FR4 lossy substrate and the ground plane is located on the other side of the substrate. The proposed design of the antenna is printed at a length of patch $30.1 \mathrm{~mm}$ and width of patch $40 \mathrm{~mm}$, it is feeding from the sides of the substrate which is connected to a RMPA. The proposed structure of the PRMA with tree shape design is created and simulated on CST [7] is shown in the Figure 2.

The dimensions of lengths and widths of the RMPA with ground plane layer are shown in tabulated form in Table 1.

Table 1: Dimension of RMPA

\begin{tabular}{|c|c|c|}
\hline Parameter & Description & Value \\
\hline Wsub & Width of Substrate & $128 \mathrm{~mm}$ \\
\hline Lsub & Length of Substrate & $128 \mathrm{~mm}$ \\
\hline Wp & Width of patch & $40 \mathrm{~mm}$ \\
\hline Lp & Length of patch & $30.1 \mathrm{~mm}$ \\
\hline Wc & Width of cut & $1.5 \mathrm{~mm}$ \\
\hline Lc & Length of cut & $9 \mathrm{~mm}$ \\
\hline Ws & Width of stripline & $2 \mathrm{~mm}$ \\
\hline Ls & Length of stripline & $25.95 \mathrm{~mm}$ \\
\hline H & Height of substrate & $1.6 \mathrm{~mm}$ \\
\hline Er & $\begin{array}{c}\text { Dielectric Constant } \\
\text { (FR4 Lossy) }\end{array}$ & 4.3 \\
\hline Wg & $\begin{array}{c}\text { Width of Ground } \\
\text { plane }\end{array}$ & $128 \mathrm{~mm}$ \\
\hline Lg & $\begin{array}{c}\text { Length of Ground } \\
\text { plane }\end{array}$ & $128 \mathrm{~mm}$ \\
\hline
\end{tabular}

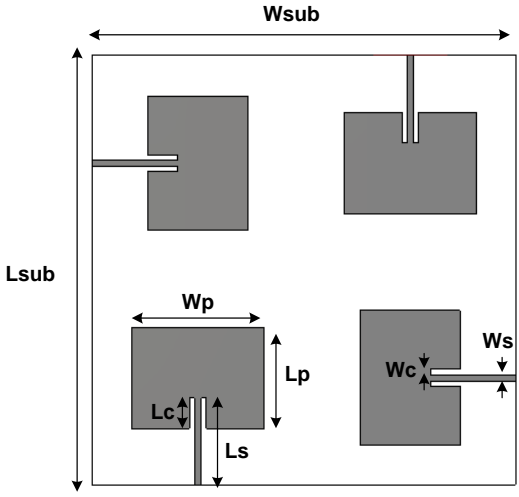

(a)

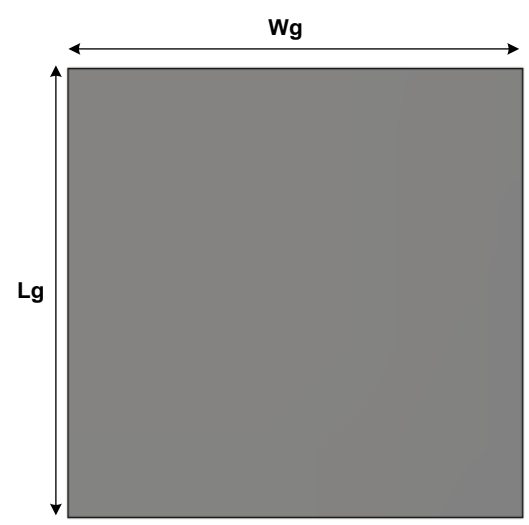

(b)

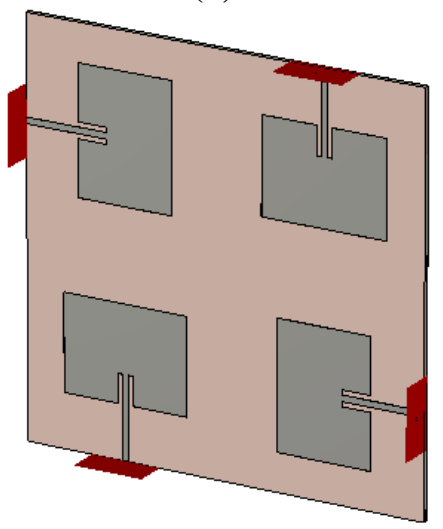

(c)

Fig. 2: Structure of the MIMO RMPA with Tree Shape patch.
(a)
Front View (b) Back View (c) 3D view

\section{SIMULATION AND EXPERIMENTAL RESULTS}

The 2x2 MIMO RMPA with tree shaped patch and an etched ground plane was simulated using the CST Microwave Software. The simulated return loss \& bandwidth of the rectangular microstrip patch MIMO antenna is shown in Figure 3. The simulations are performed using the CST Microwave Studio Software. It is shown that the bandwidth of antenna is $69 \mathrm{MHz}(3.503 \mathrm{GHz}$ $3.572 \mathrm{GHz}$ ) at a return loss of $-24.1 \mathrm{~dB}$ with a resonant frequency of $3.53 \mathrm{GHz}$.

Published By:

Blue Eyes Intelligence Engineering

and Sciences Publication

(C) Copyright: All rights reserved. 


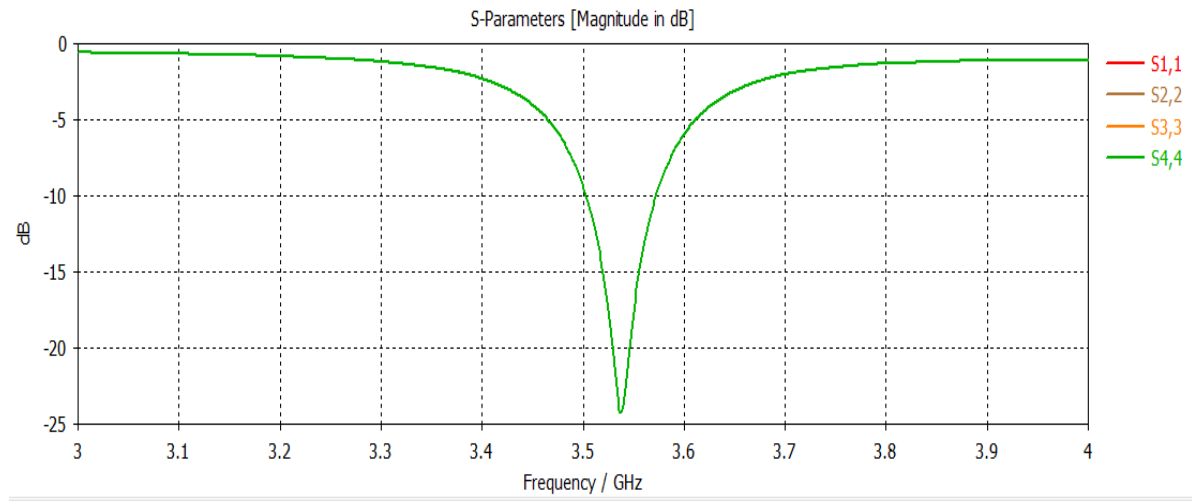

Fig. 3: Return loss of antenna 1-4

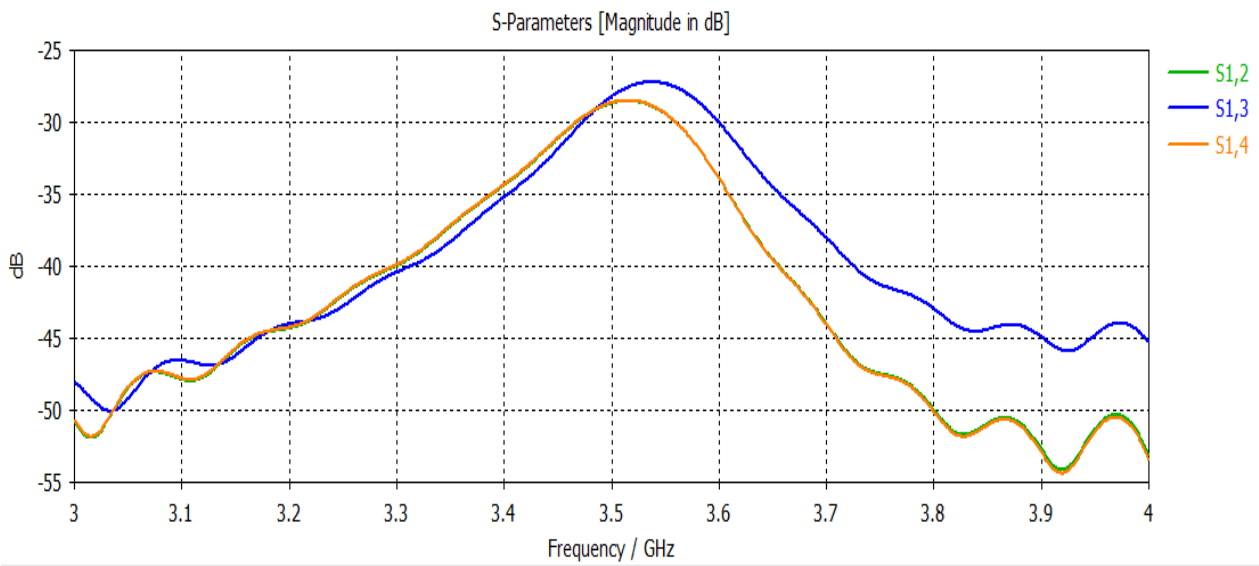

(a)

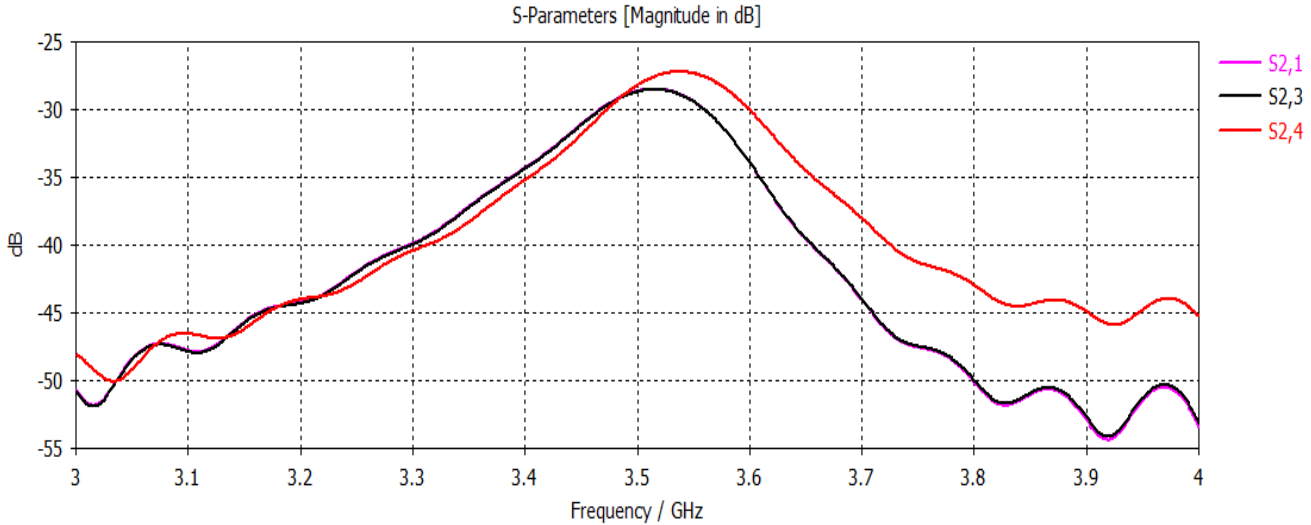

(b)

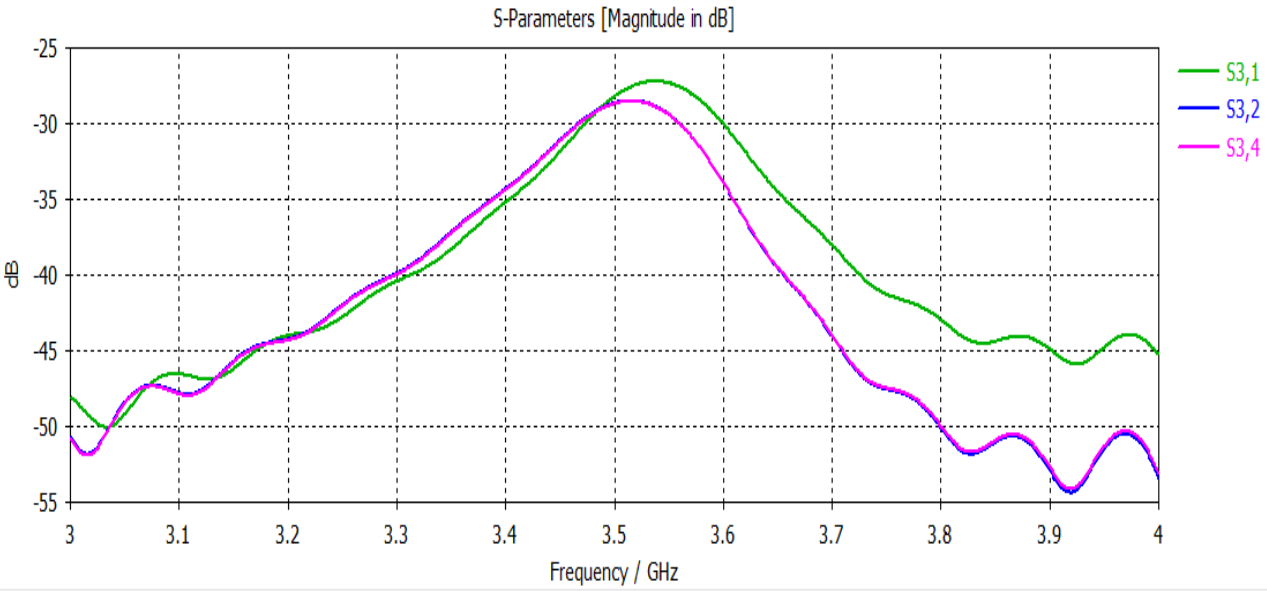

(c)

Published By:

Blue Eyes Intelligence Engineering and Sciences Publication C) Copyright: All rights reserved. 


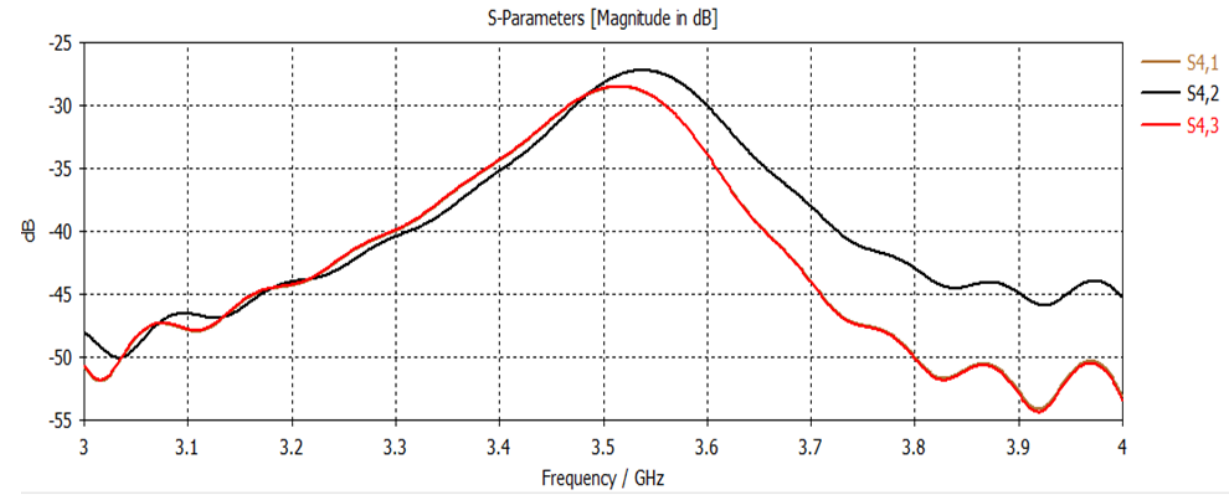

(d)

Fig. 4: Port to Port return loss of all antenna elements

The port-to-port isolation is defined as the ratio between the powers fed into one port of the antenna to the power received at the other port. It is therefore an important parameter to consider if the antenna is to be used with a transmitter that makes use of MIMO. All the isolations between the ports are shown in Figure 4.

The 3D view of simulated radiation pattern at $3.53 \mathrm{GHz}$ is shown in Figure 5. In the Figure 5, it is clear seen that directivity of antenna is $6.835 \mathrm{dBi}$.

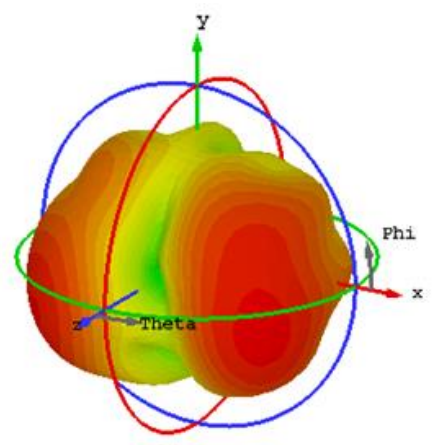

Fig. 5: 3D view of radiation pattern at $3.538 \mathrm{GHz}$

E- Plane of proposed MIMO antenna at a resonant frequency of $3.538 \mathrm{GHz}$ is shown in Figure 5. It is clearly Farfield Directivity Abs (Phi=90)

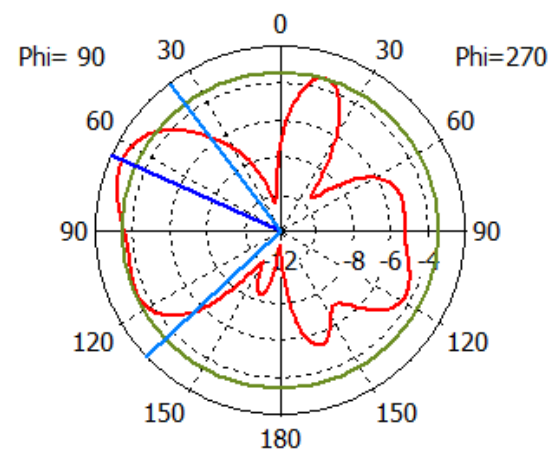

Theta / Degree vs. dBi

(b) visible in Figure 6(a) that radiation is bi-directional in nature with a half power beam width of 47.5 degree. Similarly, $\mathrm{H}$ plane of proposed MIMO antenna at a resonant frequency of $3.538 \mathrm{GHz}$ is shown in Figure 6(b). It is clearly visible in Figure 6 that radiation is omnidirectional in nature with a half power beam width of 96.2 degree.

$$
\text { Farfield Directivity Abs (Phi=0) }
$$

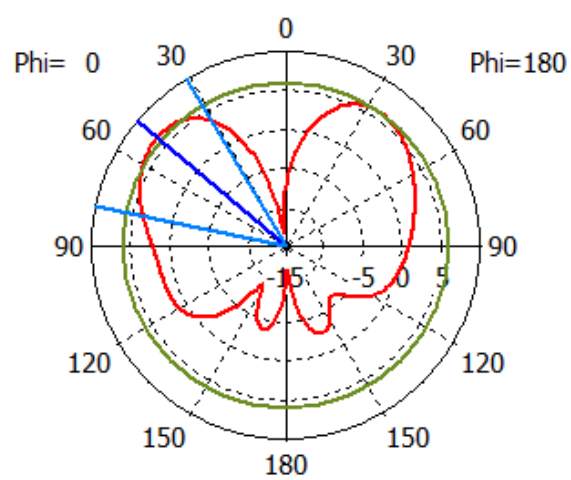

Theta / Degree vs. dBi

(a)

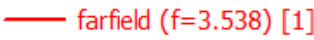

Fig. 6: Simulated Polar view of radiation pattern (a) E Plane (b) H Plane

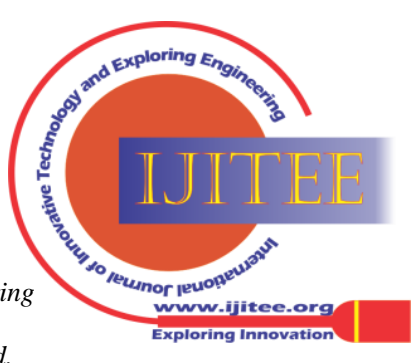




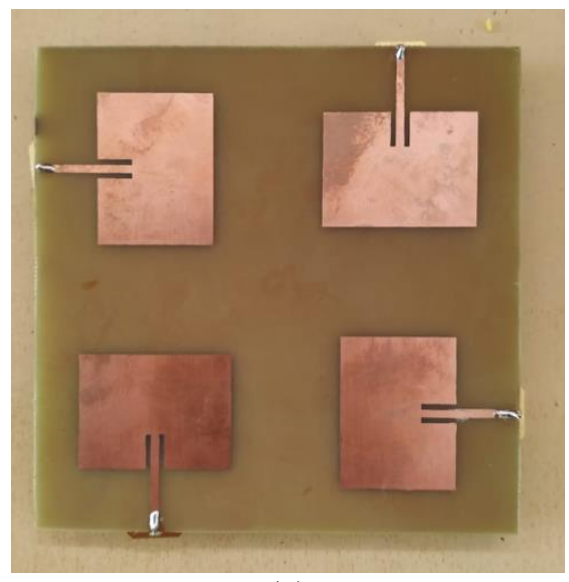

(a)

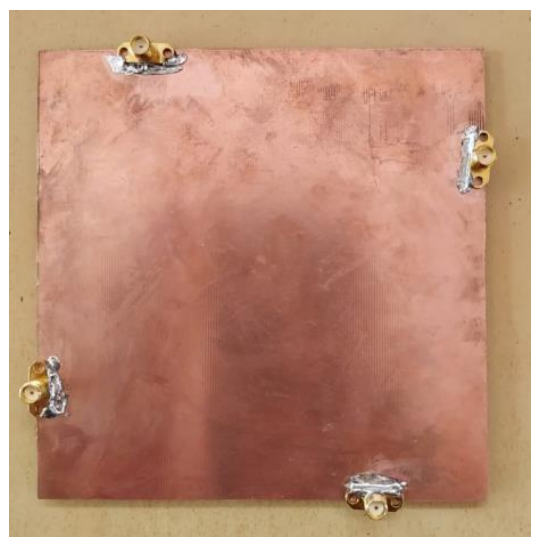

(b)

Fig. 7: Fabricated MIMO Antenna (a) top view (b) bottom view

(a)

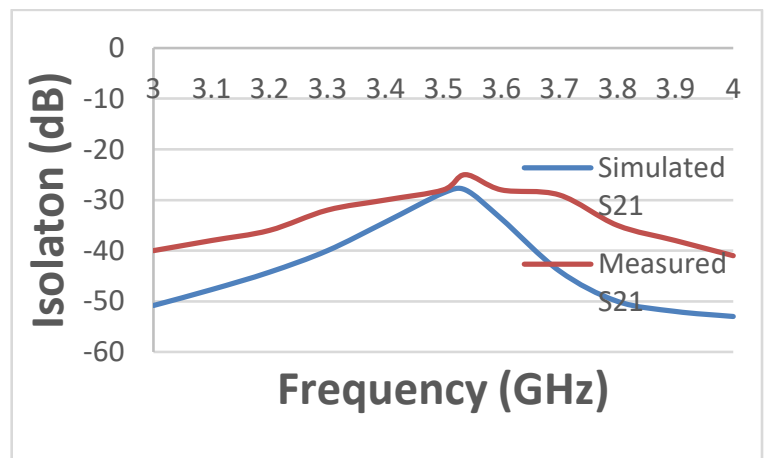

(b)
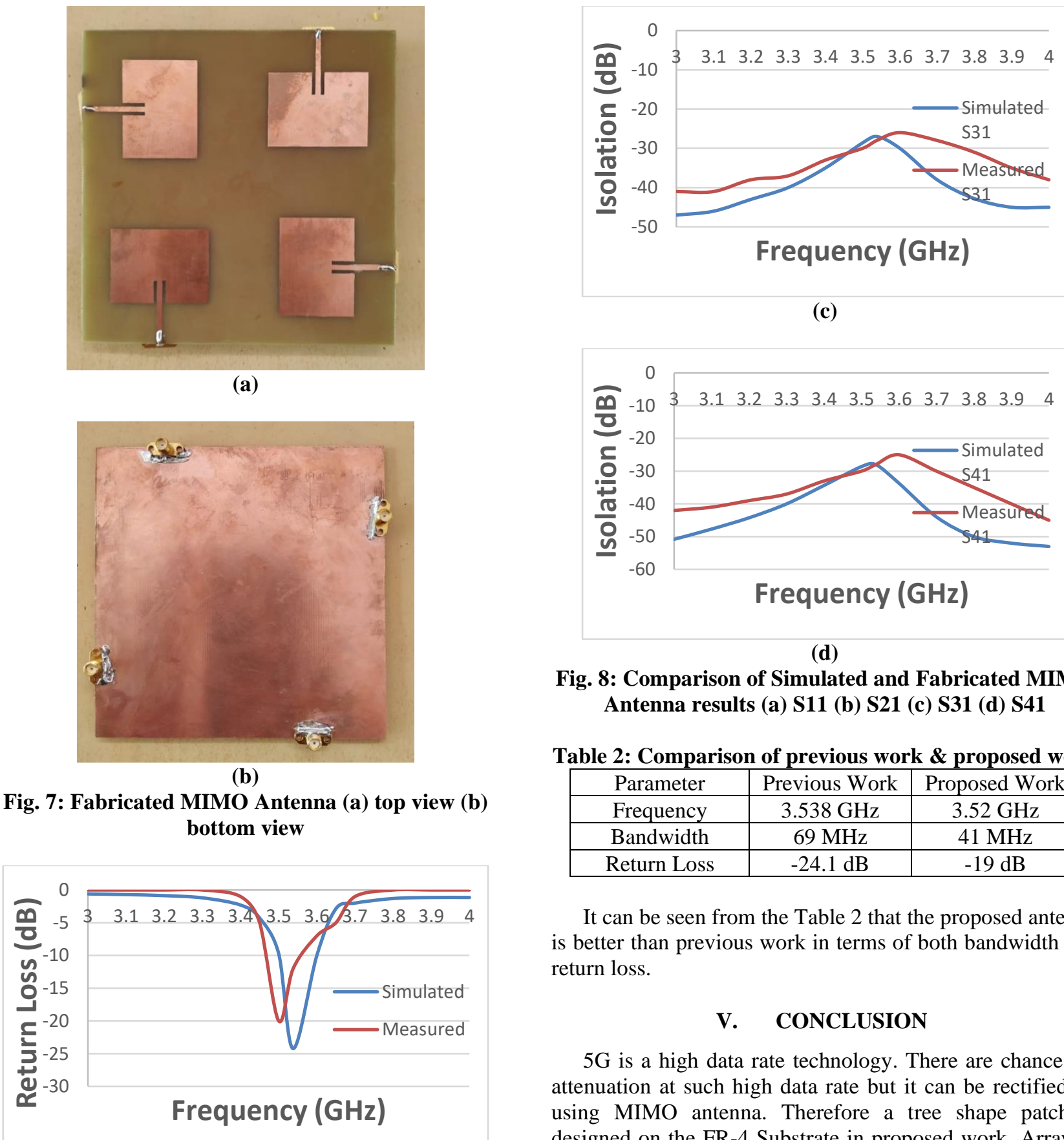

(c)

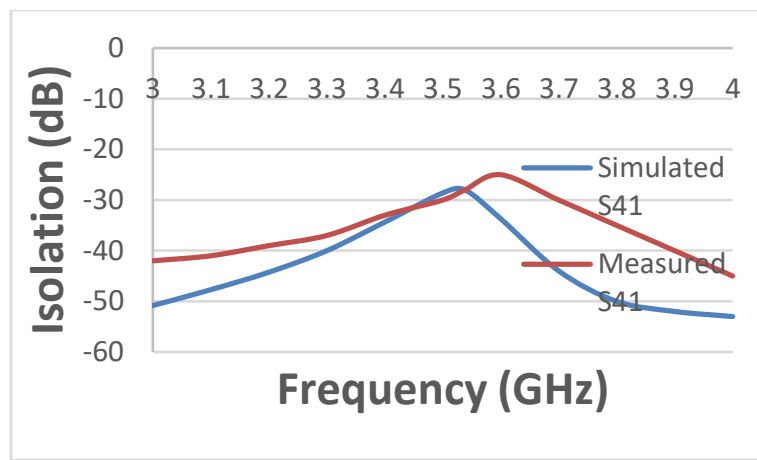

(d)

Fig. 8: Comparison of Simulated and Fabricated MIMO Antenna results (a) S11 (b) S21 (c) S31 (d) S41

Table 2: Comparison of previous work \& proposed work

\begin{tabular}{|c|c|c|}
\hline Parameter & Previous Work & Proposed Work \\
\hline Frequency & $3.538 \mathrm{GHz}$ & $3.52 \mathrm{GHz}$ \\
\hline Bandwidth & $69 \mathrm{MHz}$ & $41 \mathrm{MHz}$ \\
\hline Return Loss & $-24.1 \mathrm{~dB}$ & $-19 \mathrm{~dB}$ \\
\hline
\end{tabular}

It can be seen from the Table 2 that the proposed antenna is better than previous work in terms of both bandwidth and return loss.

\section{CONCLUSION}

$5 \mathrm{G}$ is a high data rate technology. There are chances of attenuation at such high data rate but it can be rectified by using MIMO antenna. Therefore a tree shape patch is designed on the FR-4 Substrate in proposed work. Array of 2x2 is developed on same PCB to develop a MIMO system which is capable of sending multiple data at a time and thus increase the data rate. The proposed MIMO design is providing bandwidth of $69 \mathrm{MHz}$ which is better in comparison with previous work. The return loss of $-24.1 \mathrm{~dB}$ is achieved at the $5 \mathrm{G}$ frequency of $3.53 \mathrm{GHz}$. The proposed design is suitable for $5 \mathrm{G}$ applications.

\section{REFERENCES}

1. Nuhung Suleman and Rahmat, "Design of Multiband MIMO 2 × 2 Microstrip Antenna with Multi-slot Method", International Journal of Applied Engineering Research, Volume 12, Issue 19, 2017.

2. Arwa Abdulkareem, Malik Jasim Farhan, "A Novel MIMO Patch Antenna for 5G Applications", ICEAT 2020, IOP Conf. Series: Materials Science and Engineering, Volume 870, 2020.

Published By:

Blue Eyes Intelligence Engineering

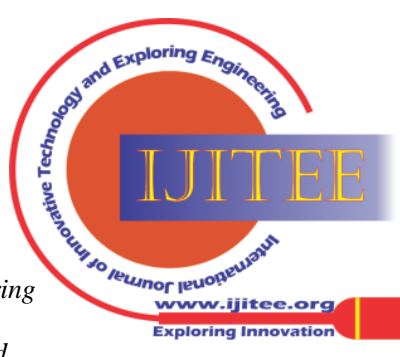


3. Sweety Jain, Vandana Vikas Thakare, "Design and analysis of compact microstrip circular resonator with slotted in ground plane as a grain moisture sensor", Review of Information Engineering and Applications, Conscientia Beam, Volume 7, Isuue 1, June 2020.

4. Daniyal Ali Sehrai, Mujeeb Abdullah, Ahsan Altaf, Saad Hassan Kiani, Fazal Muhammad, Muhammad Tufail, Muhammad Irfan, Adam Glowacz and Saifur Rahman, "A Novel High Gain Wideband MIMO Antenna for 5G Millimeter Wave Applications", Electronics 2020, 9, 1031; doi:10.3390/electronics9061031.

5. BanothuYVNRSwamy, Polepalli Siddaiah, "Design of a Compact $2 \times 2$ Multi Band MIMO Antenna for Wireless Applications", International Journal of Recent Technology and Engineering (IJRTE), Volume-7 Issue-6S2, April 2019.

6. S Jain, PK Mishra, VV Thakare, "Rice moisture detection based on oven drying technique using microstrip ring sensor", Engineering Vibration, Communication and Information Processing, Oct 2018.

7. Mousami Soni, Prof. Mahesh Goud, "Designing And Analysis Of 2x1 MIMO Antenna Using Full Ground And Slotted Ground For Wireless Application", International Journal Of Engineering Sciences \& Research Technology, Volume 6, Issue 8, August 2017.

8. Altaf, A., Alsunaidi, M.A.; Arvas E., "A novel EBG structure to improve isolation in MIMO antenna" Proceedings of the IEEE USNC-URSI Radio Science Meeting (Joint with AP-S Symposium), San Diego, CA, USA, July 2017.

9. Haq, M.A.U.; Khan M.A.; Islam, M.R. "MIMO antenna design for future $5 \mathrm{G}$ wireless communication systems", In Software Engineering, Artificial Intelligence, Networking and Parallel/Distributed Computing; Springer: Cham, Switzerland 2016.

10. Costa, J. R., E. B. Lima, C. R. Medeiros, and C. A. Fernandes, "Evaluation of a new wideband slot array for MIMO performance enhancement in indoor WLANs," IEEE Transactions on Antennas and Propagation, Volume 59, Issue 84, 2011.

11. Zhang, S., P. Zetterberg, and S. He, "Printed MIMO antenna system of four closely spaced elements with large bandwidth and isolation," Electronics Letters, Volume 46, Issue 15, 2010.

\section{AUTHORS PROFILE}

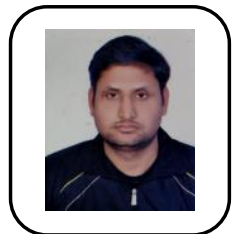

Jitendra Dubey, received degree in Bachelors of Engineering in stream Electronics \& Communication from Maharana Pratap College of Technology Gwalior Madhya Pradesh India in 2014. He is currently pursuing his M.Tech in Stream Microwave Engineering from Madhav Institute of Technology \& Science Gwalior Madhya Pradesh. He is working on MIMO based Microstrip patch antenna for the applications of 5G technology.

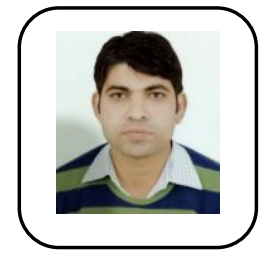

Santosh Sharma, received his bachelor degree from MITS gwalior India and Master degree from MNNIT Allahabad. Currently working in Microstrip Antenna Design field. Till date He is having fourteen papers at national and international level. He is a lifetime member of The Institute of Electronics \& Telecommunication Engineers (IETE) and IEANG.

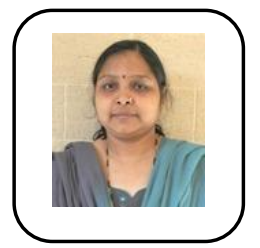

Vandana Vikas Thakare, was born in 1976, received her bachelors degree in 1999 from from Government college of engineering Jabalpur, Madhya pradesh India. She got her Masters degree in 2003 from MITS Gwalior India. .She Completed her PhD from RGPV Bhopal, India on "Microstrip patch Antenna Design using Artificial Neural Network " in 2011. Currently She is Working as Associates professor MITS gwalior in Electronics Department. Till date she has 150 publication in journals and conference, national and International level. She is a fellow member of aeronautical Society of India (AeSI), Institute of engineering (IE), and fellow Member of India society of Technical Education.

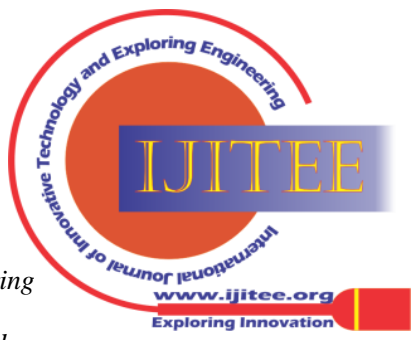

